\title{
The Effects of the Price Change, on the Demand of Agricultural Products During Summer Time.
}

\author{
Assoc. Prof. Dudi SULI ${ }^{1}$, Gjergji Xhabija ${ }^{2}$
}

\begin{abstract}
:
A fall in the price of a good has two effects. First, consumers enjoy an increase in real purchasing power, they are better of because can buy the same amount of the good for less money, and thus have money left over for additional purchases. The will tend to consume more of the good that has became cheaper and less of those goods that are now relatively more expensive. Both effects happen simultaneously, but it will be useful to distinguish between them in our analysis. The Demand Function and Slutsky Equation during the summer time in our products, tomato and cucumber confirms the economic theory of chain effect in the agricultural products. Our research is based to the face-toface questions about the prices that consumers receive, and to the theoretical approach to identify these effects. The demand function for this product gives us the solution of how individual's utility-maximizing choices respond to changes in income and in the prices of tomatoes and cucumbers.
\end{abstract}

Keywords: Slutsky Equation, Income Effects, Substitution, Total Effects, Normal Good

\section{Introduction}

Albanian agriculture is faced with various problems, which come from the producers but also by lowering the purchasing power of consumers. Producers are facing big problems in terms of the high competition that is done to domestic production from imported agricultural products. Imported products come in our country at lower prices since agricultural production in our country is faced with the problem of a high cost products that is affected by old technology in agricultural production in the country.

It should mention the fact that this type of product is produced by the old technology that makes it come close to the customer in very large quantities during the summer season. Therefore during the winter, market is largely

${ }^{1}$ Department of Agricultural Political Economy

${ }^{2}$ Departament of Finance and Accounting,

Agricultural University of Tirana, Albania 
dominated by imported products and in the summer there is and increased product supply due to the age of domestic agricultural products market. For the reason that the products supply increases, products according to market rules should lower their price. To measure the impact done by the large appendage of domestic agricultural products to their markets during summer; we should evaluate this difference by measuring changes in the prices of products, which is the difference between prices during summer and winter time.

\section{Methodology}

\section{Data and Methods}

The market of agricultural products in our country undergoes major changes due to the increase of domestic production during the summer season. To determine this change we will apply the change in the price of tomato product in Albania, therefore the change that makes consumer income change the price of tomatoes in the winter and summer. This price change will give different effects in terms of consumer behavior towards these products; to observe these effects we will use Equation Slutsky. Effects caused by the change of the price of tomatoes will be the Substitution Effect and the Income Effect.

When the price of goods changes, two types of effects subsist: changing rates which can switch one good for another and changing the overall purchasing power of your income. To illustrate this we will take in consideration the price of tomato. For instance, if tomatoes become cheaper, it means that you have to give up of buying less cucumber to buy more tomato (as the price of tomato has decreased). Changing the price of tomatoes has changed the rate at which the market allows you to replace the tomatoes with cucumber - has changed the correlation between the two consumer goods market represents.

At the same time, if the price of tomato decrease, this means that your monetary incomes will buy more tomato and the purchasing power of your money is growing; in spite of this the amount of money in consumers' pockets remains the same, they can buy more amounts of tomato.

The first change in the application due to the change in the exchange rate between two goods-called substitution effects. The change in the demand due to the change in the exchange rate between two goods is called substitution effect. The second effect, change in the demand due to owning more purchasing power that comes as a result of the use of savings in the first case (in the substitution effect) is called the income effect. These are only approximate definitions of both effects. In order to give a more precise definition we should examine in details the two effects. 
These effects are present in normal goods and inferior goods. To normal goods these effects reinforce each other and remain loyal to the law of demand. This means that a decrease of the tomato demand will bring an increase of the quantity purchased and vice versa.

To determine the prices of the summer and winter seasons for tomatoes we will take the average of the price of tomatoes during December to observe the price level of this product in the winter season and the average price of tomatoes in July for the first price level in the summer season.

\section{Substitution Effect}

This is better explained in Figure 1. In this picture we have a given situation in the Albanian market during the summer season in which tomato price is reduced. This means that the budget line rotates around the vertical suspension $\mathrm{m} / \mathrm{p}_{2}$ and becomes flatter. This line movement can be divided into two large budgets: first spin around the basket budget line initial search and then move right off the line required a new spin to the basket.

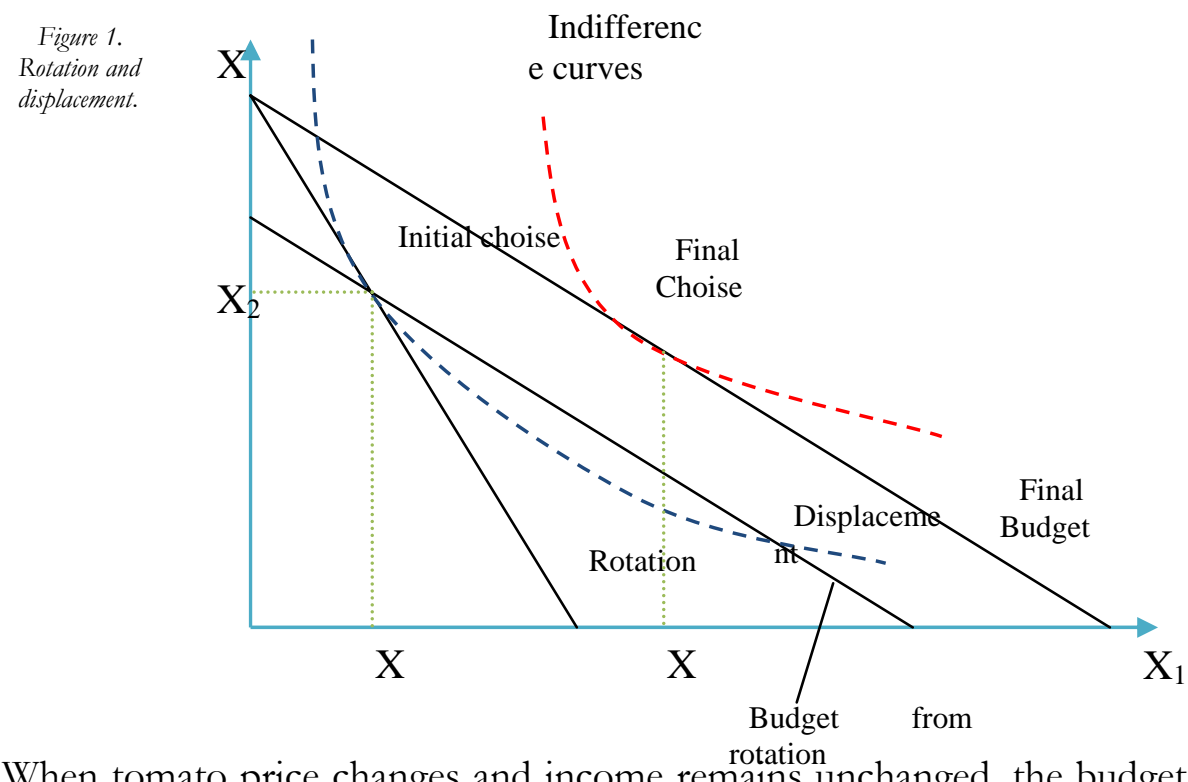
line rotates around the vertical axis. This deal will be looked as occurring in two stages: first, spin the budget line around the initial selection and then displace the line from the outside to the new basket required. This action "spin-shift" adequately gives us opportunities to break into two parts the change in demand. 
The first step, rotation is a movement where the slope of the budget line changes while its purchasing power remains unchanged. The second step is a move where the slope remains unchanged and purchasing power change.

When analyzing how consumer choices change, it is useful to assume about changing the budget line in two stages - first rotation and then shift.

We have a budget line with the same slope and therefore the same relative prices and as well as the final line of the budget. However, monetary income that belongs to this budget line is different, whilst the vertical cut is different. Despite the fact that, initial basket of consumer $\left(\mathrm{x}_{1}, \mathrm{x}_{2}\right)$ is located in the rotating line budget, precisely the consumption basket is affordable. Consumer purchasing power has remained untouched in the sense that the very initial basket of goods is an affordable new line spin.

Let's calculate how much should adjust the monetary income in order to maintain affordable old basket. We will consider $m^{\prime}$ as the amount of cash income that will make affordable initial basket of consumption; this will be the amount of cash income that corresponds to the rolling line of the budget.

While $\left(\mathrm{x}_{1}, \mathrm{x}_{2}\right)$ is affordable for $\left(\mathrm{p}_{1}, \mathrm{p}_{2}, \mathrm{~m}\right)$ and $\left(\mathrm{p}_{1}^{\prime}, \mathrm{p}_{2}^{\prime}, \mathrm{m}\right)$ have:

$$
\begin{aligned}
& m^{\prime}=p_{1}^{\prime} x_{1}+p_{2} x_{2} \\
& m=p_{1} x_{1}+p_{2} x_{2}
\end{aligned}
$$

Subtraction of the second from the first equation gives:

$$
m^{\prime}-m=x_{1}\left[p_{1}^{\prime}-p_{1}\right]
$$

This equation shows that the necessary change in the monetary income to make inexpensive the old basket, with new prices is precisely the initial quantity of tomato consumption multiplied by the change in prices.

Admitting that $p^{\prime}=\Delta x_{1} \Delta p_{1}$ present the change in the initial price of tomato and $\Delta m=m^{\prime}-m$ represent the necessary change of the incomes, in order to make the old basket affordable,

we have:

$$
\Delta m=x_{1} \Delta p_{1}
$$

At this point we have a formula for the line rolling budget; it is exactly the new budget line with the price of changing income $\Delta \mathrm{m}$. It can be observed that if the price of tomatoes decreases, then the adjustment in income will be negative. When a price falls, consumer purchasing power increases, thus it is needed to reduce the income of the customer in order to keep the purchasing power unchanged. Generally speaking $\left(\mathrm{x}_{1}, \mathrm{x}_{2}\right)$ continues to be affordable; it is not the optimal buying in the rolling budget line. In figure 1 we have noted $Y$ the optimal buying in the rotating budget line. This basket of goods is the optimal 
basket of goods, that when the price is changed and then the income is arranged into dollars, in such a way to keep the old basket of goods affordable. Moving from $X$ to $Y$ is known as the substitution effect. It shows how the consumer "replaces" a good with another when a price is changed although the purchasing power remains unchanged. Nevertheless, the substitution effect $\Delta \mathrm{x}_{1}{ }^{2}$, is the change in the demand for tomato price in winter when the price of good 1 changes $\mathrm{p}_{1}$ and simultaneously changes in monetary income $m^{\prime}$ :

Figure 2

Substitution effect and Income effect.

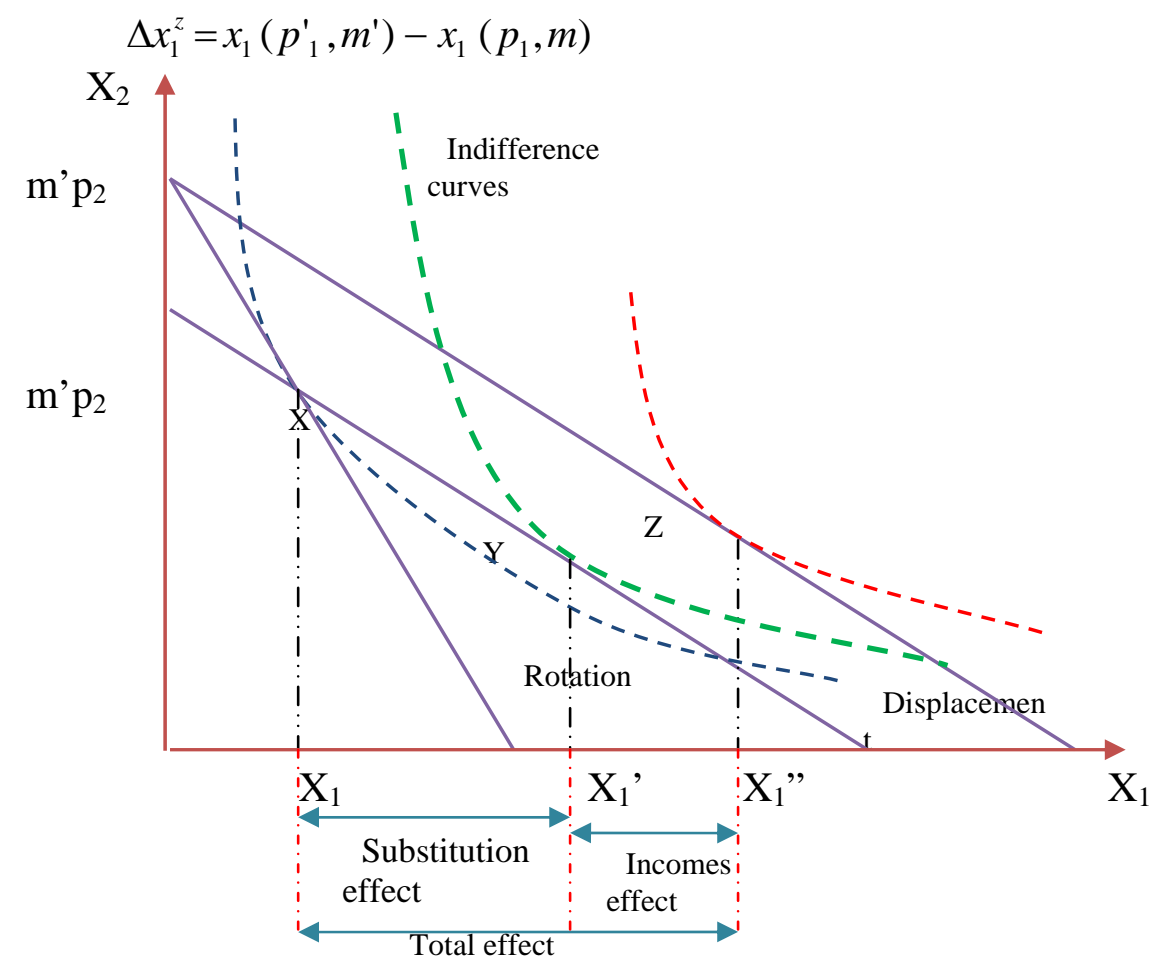

The rotation gives the substitution effect and displacement gives the income effect.

In order to determine the effect of substitution, we should use consumer demand function to calculate optimal selections in $\left(\mathrm{p}_{1}{ }^{\prime}, \mathrm{m}^{\prime}\right)$ and $\left(\mathrm{p}_{1}, \mathrm{~m}\right)$.

Sometimes the effect of replacement is called the compensated demand change; the scheme is to compensate an increased price by returning customers enough income to buy his previous basket. Obviously if the price decreases, he will be compensated by removing him money. In general, to be in the same route we will continue with the terminology of "replacement", but also the terminology of "compensation" encloses a wide use. 


\section{Estimating the effects of replacing} form:

Supposing that the consumer has a demand function for tomatoes, to

$$
x_{1}=\frac{m}{10 \times p_{1}}-3
$$

His initial income is 6000 ALL per week and the price of tomato for winter time is 170 ALL per kilogram. As a result, his demand for tomato during winter season will be:

$$
6000 /(10 \times 170)-3=0.5 \mathrm{Kg} \text { per week during winter. }
$$

During summer season we will have a decrease of the price of tomato; it will become 80 ALL per kilogram. While, his demand with this price will be:

$$
6000 /(10 \times 80)-3=4.5 \mathrm{Kg} \text { tomato per week. }
$$

Substantial change in demand is $4.5-0.5=4 \mathrm{~kg}$ per week.

In order to calculate the effect of substituting, we should first calculate how much income would have to have the customer in order to make the very affordable initial tomato consumption so when the price of tomatoes is 80 ALL per kilogram.

$$
\Delta m=x_{1} \Delta p_{1}=0.5 \times(80-170)=-45 \text { leke }
$$

So the level of the necessary income to maintain constant purchasing power is:

$$
m^{\prime}=m+\Delta m=6000-45=5955 \text { leke }
$$

To find out which is the consumer demand for tomatoes with the new price, 80 leke per kilogram and with this income level we build the demand function and we acquire:

$$
x_{1}\left(p_{1}^{\prime}, m^{\prime}\right)=x_{1}(80,5955)=\frac{5955}{10 \times 80}-3=4.44
$$

Whilst the substitution effect is:

$$
\Delta x_{1}^{s}=x_{1}(80,5955)-x_{1}(170,6000)=4.44-0.5=3.94
$$




\section{Income effect}

Now we turn to the second phase of price adjustment, to the movement of displacement. It is also easy to interpret economically. We know that a parallel shift of the budget line that is the movement that occurs when income varies while relative prices remain unchanged. So the second phase of price adjustment is called the income effect. The simplest change of consumer income from $\mathrm{m}^{\prime}$ into $m$, by keeping the prices unchanged in $\left(\mathrm{p}_{1}{ }_{1}, \mathrm{p}_{2}\right)$. In figure 2 there is a change from $\left(y_{1}, y_{2}\right)$ into $\left(z_{1}^{\prime}, z_{2}\right)$. It is normal to have a final movement called the income effect, as only we change the income and maintain unchangeable the new prices.

More specifically the income effect $\Delta X_{1}^{a}$, is the difference in demand for the good 1 when we change the income from $m$ ' to $m$, by maintaining the price of good 1 unchangeable in $\mathrm{p}_{1}$ :

$$
\Delta X_{1}^{a}=x_{1}\left(p_{1}^{\prime}, m\right)-x_{1}\left(p_{1}^{\prime}, m\right)
$$

When the price of a good decreases, it is needed to descent the incomes in order to keep the purchasing power constant. If the product is a normal good, then this reduction in the incomes will lead to the decline of the demand.

\subsection{Estimating the effects of income}

In the given example above, we demonstrated that:

$$
\begin{aligned}
& x_{1}\left(p_{1}{ }^{\prime}, m\right)=x_{1}(80,6000)=4.5 \\
& x_{1}\left(p_{1}{ }^{\prime}, m\right)=x_{1}(80,5955)=4.44
\end{aligned}
$$

So, the income effect for this problem is:

$$
\Delta x_{1}^{a}=x_{1}(80,6000)-x_{1}(80,5955)=4.5-4.44=0.06
$$

While for this customer tomatoes are a normal good, the demand for tomatoes increases when income increases.

\section{Substantial change in demand}

Substantial change in demand $\Delta \mathrm{x}_{1}$ is the change in demand due to the price change keeping revenues unchanged: 


$$
\Delta x_{1}=\left(p_{1}, m\right)-X_{1}\left(p_{1}, m\right)
$$

We have seen above how this change can be decomposed in two changes:

Substitution effect and the income effect, expressed by symbols defined above

$$
\begin{gathered}
\Delta x_{1}=\Delta x_{1}{ }^{2}+\Delta x_{1}{ }^{a} \\
x_{1}\left(p_{1}, m\right)-x_{1}\left(p_{1}, m\right)=\left\lfloor x_{1}\left(p_{1}, m\right)-x_{1}\left(p_{1}, m\right)\right]+\left\lfloor x_{1}\left(p_{1}, m\right)-x_{1}\left(p_{1}, m\right)\right\rfloor
\end{gathered}
$$

Explicitly this equation declares that the substantial change in the request is equal to the substitution effect plus the income effect. This equation is called the Slutsky identity. We observe that this identity is real for all values of $p_{1}, p^{\prime} m$ and $m^{\prime}$. The first and the fourth term on the right are simplified; therefore the right is totally equal with the other on the left.

In our case we will have:

$$
\begin{aligned}
& \Delta x_{1}=\Delta{x_{1}}^{2}+\Delta x_{1}{ }^{a} \\
& \Delta x_{1}=3.94+0.06 \\
& \Delta x_{1}=4
\end{aligned}
$$

Filling Slutksy identity is not purely algebraic identity- namely a common mathematics occurrence. Filling deals with the interpretation of the two terms of the right side: the effect of substitution and income effect.

\section{Conclusions}

Tomatoes are a normal good and for this reason, the decline in prices during the summer season (as evidenced by this survey in the market) will lead to the growth of the quantity bought tomatoes. In the case of normal goods, income and substitution effects work in the same direction. Demand change due to the change of the price of tomatoes while keeping in reserve money provided by the account for the effect of the replacement price reduction.

In this case shows that consumer preferences do not change so stay on the same indifference curve. In case of price change and use the revenue obtained by lowering the price makes the demand increase, this is the income effect. The socalled income effect makes that we consume more as a result of the reduced 
price. After applying the Slutsky equation only confirmed that during the summer season of consumer purchasing power increases due to changes in relative prices pack that income does not change.

\section{References}

SULI, D. D. (2003). Mikroekonomi e Ndermjetme. Tirane: UBT.

SULI, D. (2012). Eficensa Ekonomike.

Salvatore, D., \& Diulio, E. (1993). Priciples of Economics. Orlando.

Varian, H. R. (1990). Intermediate Microeconomics. Michigan: W.W.Norton \& Company.

Mankiew, G. (1998). Principles of Microeconomics.

Pindyck, R. S., \& Rubinfeld, D. L. (1994). Microeconomics. New Jersey: Prentice-Hall, Inc.

Baumol, W. J., \& Blinder, A. S. (1991). Economics. New York.

Dong, D., Gould, B. W., \& Kaiser, H. M. (2003). Food Demand in Mexico: An Application of the Amemiya-Tobin Approach to the Estimation of a Censored Food System. Amrican Journal of Agricultural Economics, 4-9.

Gazeta Shqip. (2009, October 28). Produktet Bujqesore, ankohen konsumatoret. Gazeta Shqip, pp. 4-5.

Putler, D. (1992). INCORPORATING REFERENCE PRICE EFFECTS INTO A THEORY OF CONSUMER CHOICE. Marketing Science; Summer92, Vol. 11 .

Ruli, G. M. (2010, July 14). Ndryshimet klimaterike rritën çmimet e produkteve, por pati progres. (G. Metropolitan, Interviewer) 
